\section{How lead generation can be the link between marketing and sales through the customer experience? A case study of Talentia Software Italy}

\section{Arianna Di Vittorio}

Department of Economics, Management and Business Law, University of Bari "Aldo Moro" Bari, Italy

\section{Di Gioia Vito Alessandro}

Department of Economics, Management and Business Law, University of Bari "Aldo Moro" Bari, Italy

Submitted: 16 November 2020

Accepted: 11 December 2020

Published: 31 December 2020

Corresponding author:

Arianna Di Vittorio

DOI: 10.19044/esj.2020.v16n34p45

(a)

Copyright 2020 Di Vittorio A. \& Di Alessandro G.V. Distributed under Creative Commons BY-NC-ND 4.0 OPEN ACCESS

\begin{abstract}
Digitalization is the use of digital technology to adapt and grow a business model. Businesses use digitalization to create value-producing opportunities through the information they collect from customer interactions by optimizing their marketing and selling processes. Potential customers have changed the way that they research and select products and services, so companies must respond and adapt. Competition has increased so creating win-win customer relationships is even more important today than ever before. Due to the uniqueness of the contemporary digital economy, brands may need to redefine what profit means for both company and consumer. The Customer Lifetime Value Analysis is the potential value of all future profit that an individual customer will generate over the life of potential customer compared with the benefit expected for both parties. First of all, the premise of the paper considers the process of scouting for new and potential customers value for money and value for time are highly relevant for brands. The most important recommended methods are Advertising (it helps to offer a message that not only hits on brands target customers, but also showcases the value brands can offer them); Networking and referral (to pick up customers with the highest retention rates; what is more, referral customers tend to purchase more over time and in turn become a source of additional referrals); Create an agreement with "host beneficiary" (another business with the same target customer will use their database to promote another one business); Strategic alliances (while a host beneficiary relationship is generally a onetime or short-term commitment, strategic
\end{abstract}

Di Vittorio A. \& Di Alessandro G.V.,(2020). How lead generation can be the link between marketing and sales through the customer experience? A case study of Talentia Software Italy. European Scientific Journal, ESJ, 16(34), 45. https://doi.org/10.19044/esj.2020.v16n34p45 
alliances can sometimes last for many years). Then, the aim of the paper is to demonstrate the relevance of the role of the Business Developer through Lead generation. It is more profitable if brands take the approach of using live chat services, direct help options with customer representatives present to solve any incoming query. This works by increasing engagement on the customer level and increases brand word of mouth promotion for more leads and better business development. Moreover, the paper analyses the roles of the Demand Generation Manager, Inside Sales Representative and more are at the core of Business Development. The methodology used in the paper is a descriptive empirical analysis. After a view on the important variables about business development analysis, lead generation and customers experience, the Authors describe the strategies adopted in the case history (Talentia Software Italy). This empirical analysis aims to confirm the validity of the concept that confirms a really and strong relation between lead generation attitudes and marketing sales.

Keywords: Lead generation, Marketing Sales, Business Development, Customer Experience

\section{Introduction}

\section{Business Development and Lead Generation}

Scott Pollack (2018) sought to define the different types of business development in one comprehensive framework, and at the end of his work he said: "Business development is the creation of long-term value for an organization from customers, markets, and relationships".

Steve Martin (2018), professor of Sales Strategy at the University of Southern California, thought about sales and marketing: "They are able to create a transactional engagement and the focus is on opening opportunities. They require analysis and strategy as much as research and data control."

About the definitions, there is elegance in simplicity, but perhaps there is something more considering that relationship and opening opportunity have a great deal in common.

So, the questions are: Are contemporary marketing and sales processes closer than before? If the answer is yes, then what about Lead Generation?

Salesforce.com define "lead generation" as the process of being able to build relationships with prospects, to earn their trust, and be by their side until they are ready to make a purchase. In detail, lead generation is about finding quality leads and nurturing them into relationships. The B.A.N.T. Analysis (AA.VV., 2017) is one of the sales qualification frameworks used to identify and pursue the most qualified prospects based on their budget, authority, needs, and timeline.

The lead generation process can be managed remotely although the Business Development Team must be close to a potential customer. This is because sellers will feel competitive pressure to cut costs and increase revenue and buyers are more comfortable collaborating remotely through webconferences, phone calls, webinars, emails, and or social media. 
The first step in structuring a lead generation campaign is to understand how to organize the customer acquisition strategy, which in turn depends on understanding how the consumer behaves.

This understanding derives from the study of the purchasing process, summarized in this scheme:

1. Perception of need.

2. Search for information.

3. Purchase.

4. Post-purchase behaviour.

Lead generation focuses on the first point: the perception of need.

From the perception of need comes the type of demand that the company can satisfy by offering its product or service.

The perception of need can be configured in two different ways, each of which generates a specific type of question:

1. Perception need as "Discovery": The consumer discovers a product or service for the first time.

2. Perception need as "Problem": The consumer has a problem that he wants to solve.

The first case concerns a latent question: the consumer does not directly look for a product or service but may need it.

This means that the lead generation campaign must have as its first objective to stimulate the potential customer and bring him to the knowledge that he has a need.

The classic example is advertising on TV, which on the web translates into sponsored campaigns on Facebook Ads.

The second case concerns a conscious question: does the consumer know exactly what his problem or need is, and he is looking for a solution.

The acquisition channels here are different, and brands prefer to take advantage of SEO (placing site among the top positions in search engines organically) or paid ads in search engines (which allow you to appear among the first search results for an investment).

Only by analyzing the type of question it is possible deduce which customer acquisition strategy is best suited for the lead generation system to implement (and in case below it is possible see how this is sometimes not so obvious).

Intercepted the question, the next step in a lead generation campaign is to convert traffic to customers.

So, how do brands generate affiliate marketing leads? Here are three smart ways to generate new leads for Brands Affiliate Website: 
1.Offer"'new customer bonuses" to brands affiliates, by changing their commission settings; they can offer bonuses to their affiliates for each new customer they recruit.

2.Expand brand reach by writing guest posts.

3.Create (or optimize) brands social media campaigns.

Heidi Cohen (2014), Chief Content Officer at Actionable Marketing Guide, said about lead generation that: "Today's customers are social media and content marketing savvy. Whether they are making a purchase for their business or themselves, they have at least started their research before they even contact you".

Considering all these opinions, why has lead generation become an added value activity for marketing and sales nowadays?

The answer comes down to one-to-one relationships. Marketing isn't about a product; it is about the people who use them. Understanding these people will ensure the marketing has an impact. It is direct marketing where its purpose is anticipating the needs and motivating a response such as a telephone call, email, on-line click, or meeting, etc. Starting from this assumption the analytical approach of the customer journey is useful to calculate the propensity to buy. Sometimes lead generation is called telemarketing, but not only calls are useful for generating leads. According to customer omni-channel approach there are many other potential touchpoints with customers, such as telephone, press releases, websites, and events. The most important part of lead generation is the human being connected to all these tools and mediums. Focusing too heavily on said tools and mediums runs the risk of losing the attention of the potential customer that brands were trying toreach in the first place.

If the risk is real, then the next question is: is the main task of the business development team to create more than a relationship?

\section{Customized Experience}

According to experience marketing theory, the new customer is everywhere (digitalization approach) and everyone's needs vary depending on time, context, relationship and emotions. Using audience profiling to understand the target in as much detail as possible becomes more important than before. 
The experiential marketing ${ }^{1}$ uses the experiences lived by consumer as marketing tool to make the consumer perceive a higher added value, thanks to the involvement of the senses and emotions. Also, within the software sector, the need to cope with the new needs of consumer led the companies on the road to experiential differentiation. Today, consumption is no longer a private and personal act, but a real "social event" in the sense that a product is purchased not so much for its functional value, as for the meaning it assumes for those who use it or consume it and for its own social relationships. The consumer experience therefore generates a noticeable involvement for consumer and for its own social relations: the individual seeks, for this reason, products and services with a symbolic value, that allow him to fully manifest his personality. "To consume means to satisfy one's own needs, but also to create and maintain social relationships" (Douglas \& Isherwood, 1989). Therefore, the experiential marketing is based on a type of consumption, different that in the past, because it does not aim to the mere satisfaction of consumer's needs, but it has as goals his involvement, his satisfaction, the reinforcement of links with other individuals, thanks to the indispensable use of emotions. Rationality leaves place to a whole set of emotional factors that characterize the experiential purchase and impact on individual's perceptions, giving life to an experience with a high emotive content.

All this is the reason why today personalization can be the key driver.

Personalized marketing is a strategy of its own that can integrate into brands different types of marketing mediums, such as email, social media, and blogs, to generate better results.

Personalized marketing involves collecting data related to the customers and crafting marketing experiences that target specific types of customers through brand's content.

In the personalize marketing, email data are very useful. The success of campaigns will depend on how well brands collect and measure data. Whether it's email list segments or surveys, brands can collect different data to learn more about their users. It is the only way to offer more personalized experiences through your marketing campaigns.

Once brand have enough data and they start to paint a picture of their typical customer, they can begin to properly personalize their marketing campaigns.

The main benefit of personalized marketing is the ability it gives to the brands to reach specific audiences. By collecting user data from list segments,

1 Writing about experiential marketing means the particular sector of marketing that concentrates its own attention on the perceived and proved experience by consumer during the choice process and following purchase. The goal is to concentrate itself about the consumer's perception, to act directly on the leverage points that allow a greater conversion of intentions for sale. 
surveys, or studies brands can create more effective email campaigns targeting audiences based on their interests or buying habits.

Perhaps the buzzword for 2021 should be 'hyper-personalization' - the harnessing of all forms of data being used in unison across all marketing channels and customer journey stages. Embracing this approach is going to move customers from top of funnel awareness to post-purchase happiness in record time through higher and more effective engagement at every stage. So, what's the recipe that $\mathrm{B} 2 \mathrm{~B}$ or $\mathrm{B} 2 \mathrm{C}$ digital marketers need to follow to enable hyper-personalization?

There are three main ingredients to consider:

1. Engagement - Engaging customers with hyper-personalized campaigns which customize their experience with your brand or organization. According to recent findings by the Epsilon Group, $80 \%$ of consumers are more likely to make a purchase when the brand offers a personalized experience. In this qualitative study, one of the respondents reported hyper-personalized campaigns drove 3-4x more engagement with the brand. A B2B respondent reported that fullfunnel personalization has doubled its webinar and event registrations. The key here lies in collecting and analysing consumer data at every turn and investing the time and effort to understand the key trends.

2. Relevance - This is the ingredient that $\mathrm{B} 2 \mathrm{~B}$ and $\mathrm{B} 2 \mathrm{C}$ marketers need to borrow from Netflix and Amazon - it requires truly getting the right message to the right person at the right time, all the time. Many have spoken about this in the past, but brands finally have the tools and knowledge available to do it properly, by using richer behavioral data and intent data to create messaging that hits everyone's personal needs and pain points.

3. Trust - If the first two ingredients are added correctly, the third will naturally follow- trust. With so much competition in the online space, customers are going to choose the one that they trust the most - which is why reviews are now so important in every aspect of our process. Aside from customer reviews, good educational content is a prerequisite - companies need to invest in an education team that puts out instructionals and thought-leadership content, especially in video form. This type of content needs to be delivered to the customer based on their specific needs, intent, and funnel stage.

The key to making this recipe work is taking a data-driven approach that is personalized for each account and each person at every touchpoint along the buyer's journey. 
If executed properly, it will result in higher engagement, more customers, a larger pipeline, and larger account wins.

Basically, the more you know, the more tailored and engaging your approach will be because nowadays there is no such archetypical customer. In this scenario, the nurturing process becomes strategic and customising the right touch points with personalized messages could be a key driver that stands out.

It is another reason why segmentation analysis could be changed as well, but this topic requires a whole new article entirely.

\section{Introduction to Talentia Software}

Talentia Software is a leading international software group that develops and implements business management software for Human Capital Management (HCM), Finance and Corporate Performance Management (CPM).

Talentia Software has been delivering strategic HCM, Finance and CPM solutions for more than 30 years.

Talentia Software currently has offices in 9 countries around the world: France, Italy, Spain, Portugal, Greece, Switzerland, Germany, United Kingdom and Canada. The group employs 430 people, has more than 3600 clients in its portfolio and 900.000 users in all industries in over 50 countries.

For all businesses today, it is all about growth.

The specific knowledge of each industry allows Talentia Software to support clients through a variety of different stages of complex and innovative programs. To grow, companies carry out several strategic options like mergers $\&$ acquisitions, international expansion, LBO, IPO or diversification. Talentia Software interviewed CFOs \& CHROs, of which $80 \%$ say their job is continuously getting much more complex.

Talentia Software understands the huge benefit that a total solution can offer an organisation. It digitalizes and makes $H R$ and Finance complexity easier.

In detail the solutions developed by Talentia Software are ${ }^{2}$ :

1. Talentia HR Suite (Fig.1): an HRIS, HRMS and HCM software that allows to optimise and simplify your HR processes. It is a complete HR Solution to simplify and optimise your HR management from payroll to employee administration to career development. The software provides all the tools you need to help streamline the administrative side of HR as well as the strategic, such as performance evaluation, succession planning, compensation review and continuous talent development.

\footnotetext{
${ }^{2}$ https://www.talentia-software.com
} 
Fig.1 - HR Suite
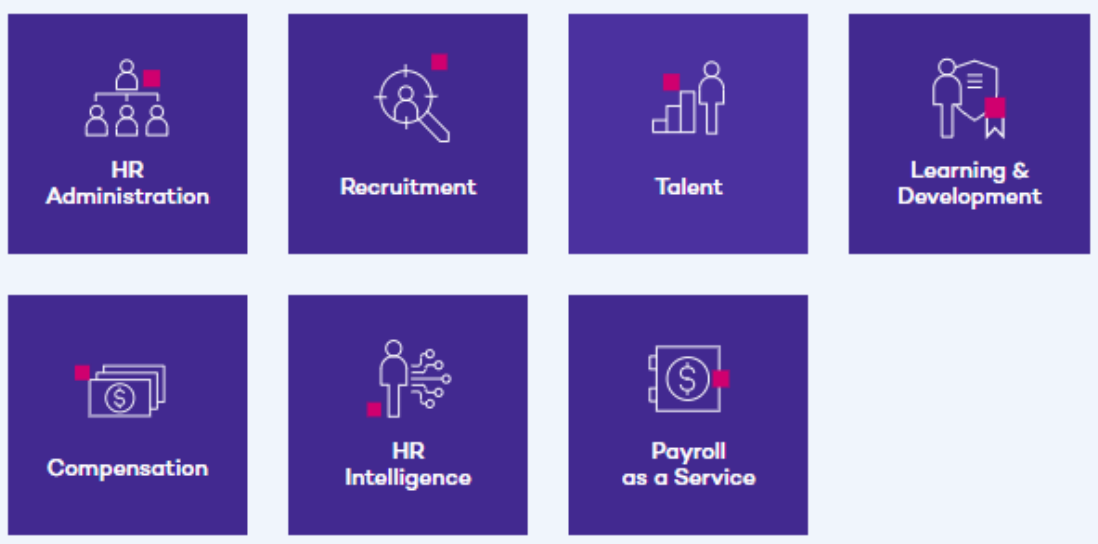

Fonte: https://www.talentia-software.com

- Strengths of the Talentia HR Suite: a complete and integrated HR platform covering HR Management, Talent Management, Payroll and T\&A, a powerful solution automating processes, offering a single source of truth with real-time business intelligence, an HRIS that adapts to changing regulatory and social constraints, an SaaS solution including recurring à la carte services, an HRIS including employee, manager and HR portals accessible on the move and simple, intuitive applications.

- Benefits of the Talentia HR Suite: your organisation becomes agile, your HR processes are simplified, and your HRIS is optimised.

2. Financial Suite (Fig.2): a single platform for financial management, performance management, consolidation and closing. Thanks to this unique software suite, financial directions benefit from digital continuity and can free up cumbersome and time-consuming tasks like controls, reprocessing, reconciliation, and regulatory management. Secured and with lot of automated processes and collaborative functionalities, Talentia Financial software solution constantly evolves and provides turnkey and adaptable business solutions.

- Strengths of Talentia Financial Suite: functional completeness, parallel core models, powerful and reviewable analytics, real time solution, integrable platform, integrated automation, reporting and analysis with adaptable granularity, instant access to detail, adaptability of the processes according to the organization, shared multi-source and multi-process piloting, simulations, and adaptable models.

- Benefits of the Talentia Financial Suite: optimizing accounting and financial operations, simplifying financial information management, 
automating reporting, forecasting \& simulations, facilitating communication, allowing real time financial performance management, Obtaining precise global and/or detailed financial performance information.

Fig.2 - Financial Suite
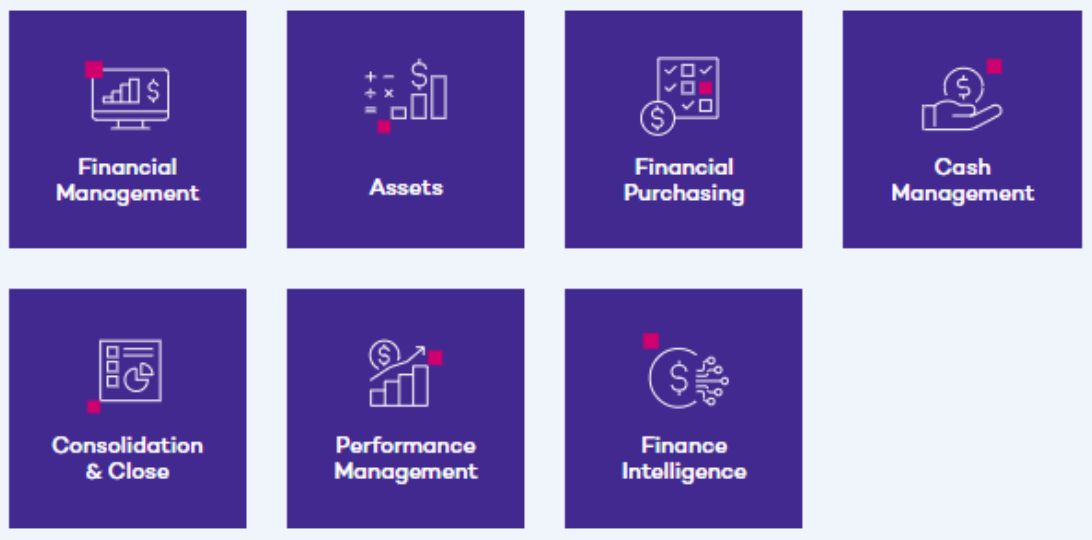

Fonte: https://www.talentia-software.com

\section{Market demand analysis, segmentation and positioning}

Analyzing the lead generation process means to deepen three key elements of business development and marketing: market demand analysis, segmentation and positioning.

In accordance with the privacy policy of the company, this paragraph considers the logical approach (modus operandi) to give the reader some food for thought.

The business development activities need to estimate the size of the markets. The market demand for a product ${ }^{3}$ is the total volume that would be bought by a particular customer group, in a particular time, in a particular marketing environment, under a particular marketing program.

Due to the market demand the marketing expenditures will increase the market demand. However, it is important to recognize three constraints in the relationship (Fig.3):

1. Market minimum, labeled in Q1 in the figure that would take without any marketing expenditure.

2. Market potential, labeled in Q2 in the figure, it is dependent on a given external marketing environment and it would occur when marketing expenditure becomes ineffective at incrementing demand.

3. Marketing forecast, labeled in $\mathrm{Qf}$ in the figure, it corresponds to a certain level of marketing expenditures, it shows the expected demand not the maximum demand.

\footnotetext{
${ }^{3}$ In this case the term product refers also to service.
} 
The distance between the market minimum and market potential indicates whether the market demand (company's target) is sensitive or insensitive to marketing expenditures.

Fig.3 - Market demand as a function of Industry Marketing Expenditure

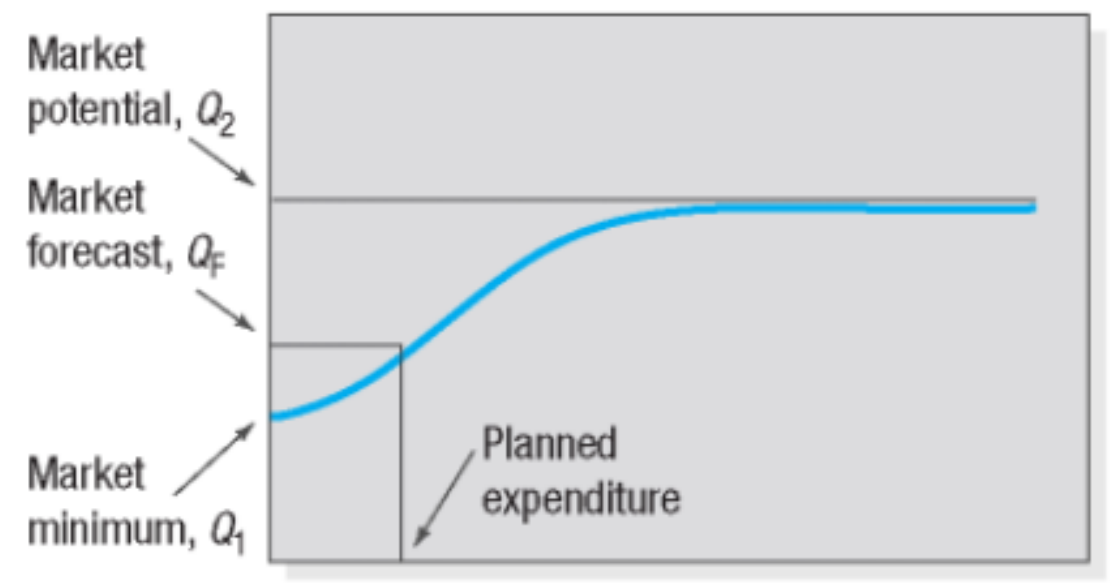

Fonte: Kotler P., Keller K. (2016). Marketing Management: Pearson (15th Ed).

Now the question is: How big are the markets for Service A and Service B? It sounds almost impossible to answer, it is possible, however, to decompose the question into sub-questions and then combine the results.

Market Build-up Methods

number of buyers in the market $\mathrm{x}$

annual quantity purchased by an average buyer $\mathrm{x}$

the average price paid per unit

$=$

\section{Market demand}

On the assumption that Service A is more profitable than Service B the next question is: what is the probability that a potential client will purchase the Service?

The answer comes down to considering the statistical modeling related to descriptive analysis such as ratio indicators: mode, median, mean, variance, standard deviation, regression analysis, etc.

According to statistic definition the regression analysis is a set of statistical processes for estimating the relationships between a dependent variable and one or more independent variables. Essentially, it is the "best guess" at using a set of data to make prediction. It is the "go-to method in analytics", and smart companies use it to make decisions about all sorts of business issues (Gallo, 2015). 


$$
\begin{aligned}
& \text { Multiple (linear) regression model } \\
& \mathrm{yi}=\beta 0+\beta 1 \mathrm{X} 1 \mathrm{i}+\ldots+\beta \mathrm{kXki}+\varepsilon \mathrm{i} \\
& \mathrm{yi}=\text { dependent variable with } \mathrm{i}=1,2, \ldots \mathrm{n} \\
& \mathrm{X} 1 \mathrm{i}, \ldots \mathrm{Xki}=\text { independent variables } \\
& \beta 0=\mathrm{intercept} \\
& \beta 1 \ldots \beta \mathrm{k}=\text { regression coefficients } \\
& \varepsilon \mathrm{i}=\text { statistic error }
\end{aligned}
$$

After the marketing analysis, the next stage involves market segmentation and positioning.

Segmentation is a way of organizing clients (potential clients) into groups with similar needs, product preferences (expectations), traits, etc. Furthermore, the more successful segmentation has been constructed on the right basis. It is the reason why the segmentation could change from traditional criteria to non-traditional criteria. The assumption is that the segments are sufficiently different from one other. The key is understanding the differentiation in relations with the competitive environment.

In summary, segmentation requires the following steps:

- Understanding the benefits that the customer seeks; ${ }^{4}$

- Segmenting the market and developing prototypical customer profiles based on the customer benefits.

- Finding the observable variables most likely to discriminate among the benefit segment to identify membership in specific segments.

Once segments are identified the cluster analysis is the statistical technique useful to identify units of observations (customers, companies, etc.) based on data on relevant classifications variables. Customers who belong to the same cluster are like each other. They are dissimilar to customers outside the cluster, particularly customers in other clusters. The primary input for cluster analysis is a measure of similarity between customers, such as: correlation coefficients, distance measure and association coefficients.

The following are the basic steps involved in cluster analysis:

- Formulate the problem and select the variables to use as the basis for clustering.

- Compute the distance between customers along the variables.

- Decide on the number of clusters.

- Map and interpret the clusters.

- Apply the clustering procedure to the distance measures.

\footnotetext{
${ }^{4}$ In this case the term customer refers to potential client (prospect).
} 
The distance between two individuals is obtained through a measure called Euclidean distance.

Euclidean distance $=\sqrt{ }(\text { Xservice, } 1-\text { Xservice, } 2)^{2}+\ldots+($ Xservice, $\mathrm{n}-$ Xservice, $n)^{2}$

Xservice $1=$ represents the value of Service along variable 1 .

Xservice $2=$ represents the value of Service along variable 2 .

All steps described remain at the core of segmentation. Even if nowadays, the segmentation analysis becomes more dynamic in three ways: economics are fluctuating frequently, customer's needs and behavior can change quickly, and emerging niche and new technologies are evolving more rapidly than ever.

Trying to put together all the various elements of the marketing mix without reference to a positioning strategy is rather like trying to make sense of a 100-piece jigsaw puzzle without the benefit of the picture on the box.

Positioning is the process of distinguishing the company from competitors. It refers to the target market segment and describes the advantages that a company would like to provide its customers.

The four possible elements at the core of the positioning process are:

- Target market: the product position in the mind of customers' company.

- Frame of difference: the product category in relation to customer need.

- Point of difference: the product value that is meaningful to the target customer.

- Reason to believe: the company ability to deliver the promised point of difference.

Considering these thoughts, positioning is not an advertising strategy. It is a process that comes from a depth analysis of the company, the competitors, products, and customers.

\section{The Lead Generation Process of Talentia Software Italy}

In the last few years, Talentia Software Italy has been reorganizing its lead generation activity going beyond to a telemarketing approach.

The new approach does not put purchased contact information lists at the centre of its strategy. It finds the right prospect through searches and analysis oriented to qualifying and targeting the potential clients.

Paying attention to all details of the potential client (work experiences, background, behavior, interests, relations, etc.) become more important than ever. 
The goal is to target the right prospect in order to create a quality experience from the very first contact to build business relationships and increase new market opportunities.

The related activities are:

- Acquiring information related to prospects as well as potential clients using online and off-line resources.

- Developing one-to-one relationships with suspects as well as prospects using all mediums and means in line with their behaviours to anticipate the need and provide real-time experiences that reach the potential clients just as they want them.

- Examining the HR scenario and Finance scenario of the company targeted in order to position the offer of Talentia Software Italy.

For this purpose, a specific plan has been formulated to optimize all operations. Specifically, these operations include:

- Improving scouting techniques: acquiring the know-how to better qualify the potential client step by step from suspect to prospect, customizing scripts, documents and reports.

- Standardizing activities: setting up procedures and methodologies to better manage the flow of information in order to monitor all feedback conversations and share the opportunities with Management.

- Updating the tools that are useful to the activities of customer relationship management.

In this scenario the activities deal with the "Lead Generation Process related to the Business Development Activities" and are organized in relation to the company mission, timeline and deadlines.

In the short-term, the activities include:

- Qualification: activity in relationship with the question "who is the target?", it looks for information useful to qualify the company in line with the target and people who have authority inside the company.

- Updating data on CRM.

In the medium and long-term:

- Scouting: first step with suspects potentially interested in Talentia Software services in line with the "customer engagement strategies" concept.

- Nurturing: second step of pursuing the suspect and/or prospects providing customized information in the right time, considering all the information useful to better position the Talentia Software services in the mind of the potential client. 
The goal of the lead generation process is quite clear: to transform the prospect into a potential client, thus creating a business opportunity. For this reason, the lead generation process, in some cases, can go on for several months. Moreover, this point is crucial, considering that:

- Competition has increased, so creating win-win customer relationships is even more important today then even before.

- There is no such archetypical customer, making the nurturing process more strategic.

\section{Conclusion}

The work experience and academic background allows a deep analysis about Lead Generation. Some case studies allow for the consideration that Lead Generation can be a link between Marketing and Sales.

It suggests that Lead Generation can be updated day by day in relation to the marketplace development and customer's behavior changes.

The idea is that Lead Generation refers to a Process. Concretizing the idea of Lead Generation as a process would allow for us to increases to the company's revenues.

The competitive value generated by the new process will be effective at a time when there is a homogeneity about the process approach methodology. In this way it is possible to avoid the risk of assembling individual plans that correspond more to a tactical rather than a strategic approach $^{5}$.

In short, Lead Generation in digital marketing is the initiation of consumer interest or inquiry into products or services of a business.

The digital era has transformed the way brands do business. Gone are the days where promoting business means taking out a newspaper advertisement or launching a flyer campaign and knocking door to door.

These days, brands can focus on their target audience and research their habits using various analytics softwares. A bit like using an x-ray machine on brands data. So, brands can choose who to hit, when and how - and execute campaigns with extreme precision. This allows brands to reverse engineer their campaigns with their starting point being the end goal, the user.

Businesses must keep up and continuously adapt to develop their digital marketing strategies. Social media and Search Engine Marketing are synonymous with Lead Generation. Both play a huge and vital role in getting brands noticed and heard and set the stage for many marketing campaigns online today.

\footnotetext{
${ }^{5}$ Tactic is an option that the company might use that is comparatively easy and inexpensive to deploy, it differs by a strategy that is the plan according to a set of activities used to create a valuable position in the market.
} 
Paying attention to an omni-channel approach where there are different touch points to get in touch with the potential customer means optimize customer journeys, not just touchpoints. For this reason, the questions to ask are: Why has lead generation become an added value for marketing? How does lead generation support sales activity?

Often lead generation process focuses on relationship.

«According to the most common interpretation» (Addis, 2007), the customer experience is divided into two principal components. The first is about the attribution of the sense of the individual to the lived interaction; the second is about interaction between the individual and the bidding system. To talk about consumer experience, it is necessary that a beneficial relationship between consumer and company is created, in such a way that the individual can be involved and is able to interpret the interaction that takes place during the consumer experience. The nature of consumer experience is complex because the consumer and his choices regarding what to consume are influenced by emotional factors connected to the experiential vision.

A good experience, to be considered as such, must be "unforgettable" (Pine \& Gilmore, 1999) that is able to stir up emotions, involve all the consumer's senses and produce important transformations. This is possible through the staging of "personal" and "memorable" events that can charm consumers and entice them to come back. The more emotions that are linked to consumption, the more value that experience will be able to create, thanks to the interaction between the consumer and the product.

According to experience marketing the next questions are: can lead generation create more than a relationship? Is the lead generation process a way of creating a personalized message with the potential customer?

Answering these questions means understanding Lead Generation as a Process where the focus will be first on opening opportunities through listening and communication skills, as well as analysis and synthesis skills.

Marketers know that the marketplace has changed, and the competition is strong. For this reason, it is important to recognise that mindset and tactics can shift.

The process to capture leads and then convert them to sales is useful but not enough. Today's mantra could be to integrate data (statistical approach), nurture leads (human approach), and then expand them as an orchestrated team. The lead generation process could be an approach that focuses not on delivering standalone campaigns, but instead on optimizing a set of related cross-channel interactions and analysing data that when combined generates revenues. 


\section{References:}

1. AA.VV. (2015). Customer Engagement: Best of the Best. Forbes Insights sponsored by SAP. www.forbes.com/forbesinsights/sap_customer_engagement/index.ht $\mathrm{ml}$

2. AA.VV. (2017). The Better Way For Sales Teams To Approach The BANT Framework by SALESFORCE https://www.salesforce.com/ca/blog/2017/12/sales-teams-approachbant-framework.html

3. Addis, M. (2012). Ad uso e consumo: il marketing esperienziale per il manager. Milano: Pearson.

4. Cohen, H. (2014). The Best Lead Generation Tips Ever. https://heidicohen.com/best-lead-generation-tips-ever/

5. Costabile, M. (2012). MBA Student Book, Subject: Marketing Analysis and Strategy. Luiss Business School.

6. Di Beth, R. (2008). Rethinking Sales Management: A Strategic Guide for Practitioners. Wiley Publisher.

7. Dolan, R. J. (2000). Note on Marketing Strategy. Harvard Business School Publishing, n.1.

8. Douglas, M., Isherwood, B. (1989). The world of goods towards an anthropology of consumption. Harmondsworth, Penguin. Tr. it., Il mondo delle cose. Oggetti, valori, consumo. Bologna: Il Mulino, 1984.

9. Gallo, A. (2015). A Refresher on Regression Analysis. Harvard Business Review, n.4.

10. Giamanco, B., Gregoire, K., (2012). Tweet Me, Friend Me, Make Me Buy. Harvard Business Review, July-August.

11. Gummesom, E. (2008). Quality, service-dominant logic, and many-tomany marketing. The TQM Journal, 20 (2).

12. Gupta, S. \& Lehemn, D.R. (2003). Customers as Assets. Journal of Interactive Marketing, Vol 17, n.1.

13. Keiningam, T., Aksoy, L., Cooil, B. \& Andreassen T.W. (2008). Linking Customer Loyalty to Growth, in MIT Sloan Management Review, n.1, July.

14. Keller, K. L., Busacca, B., Ostillio, M.C. (2014). Gestione e sviluppo del brand. Milano: Egea. Ed.or.: Strategic Brand Management (Keller, K. L., 2003).

15. Kotler, P., Keller, K. (2016). Marketing Management. Pearson (15th edition).

16. Martin, S. (2018). Heavy Hitter Selling: How Successful Salespeople Use Language and Intuition to Persuade Customers to Buy. Hoboken: Wiley (USA). 
17. Oldroyd, J. B., McElheran, K., Elkington, D. (2011). The Short Life of Online Sales Leads. Harvard Business Review, n.1, March.

18. Nolan, R. \& Bennigson, L. (2003). The Future of IT Consulting in Harvard Business School Interactive Working Knowledge, n.2, March.

19. Payne, A., Frow, P., (2005). A Strategic Framework for Customer Relationship. Management. Journal of Marketing. Vol. 69, No. 4.

20. Pine, B.J., Gilmore, J.H. (1999). The experience economy. Work is theatre \& Every Business is a stage. Boston: Harward Business School Press, n.1.

21. Pollack, S. (2018). What, Exactly, Is Business Development?: A Primer on Getting Deals Done, Firneo.

22. Resciniti, R. (2014). Il marketing orientato all'esperienza. L'intrattenimento nella relazione con il consumatore. Milano: Edizioni Scientifiche Italiane.

23. Ross, S., Westerfield, R. \& Jordan, B.D. (2008). Fundamentals of Corporate Finance. McGraw-Hill/Irwin Hardcover ( $9^{\text {th }}$ ed).

24. Sarvary, M. \& Elberse, A. (2006). Market Segmentation, Target Market Selection and Positioning. Harvard, Business School Background.

25. Silk, A.J. (2006). What Is Marketing? Harvard Business Review, n.1.

26. Steenburgh, T., Avery, J. (2010). Marketing Analysis Toolkit: Customer Lifetime Value Analysis. Harvard Business School Publishing, n.27.

27. Thomas, F., Gebauer, H., Fleisch, E. (2012), Service Business Development: Strategies for Value Creation in Manufacturing Firms. Cambridge University Press, n.24.

28. Venkatesan, R. (2007). Cluster Analysis for Segmentation. Darden Business Publishing. 